\title{
The increase of diabetes mortality burden among Brazilian adults
}

\author{
Sandhi Maria Barreto, ${ }^{1}$ Valeria Maria Azeredo Passos, ${ }^{1}$ \\ Suzanne Kelly Ferreira Almeida, ${ }^{1}$ and Tiago Duarte Assis ${ }^{1}$
}

Suggested citation Barreto SM, Passos VMA, Almeida SKF, Assis TD. The increase of diabetes mortality burden among Brazilian adults. Rev Panam Salud Publica. 2007;22(4):239-45.

ABSTRACT Objective. To estimate diabetes-related deaths among Brazilian adults between 1999 and 2003 and to investigate demographic factors associated with reporting diabetes as an associated cause of death.

Methods. All deaths with diabetes as the underlying or associated cause were identified using the Brazilian Mortality Data System. Analysis was performed by sex, age, year, state of residence, and place of death. Mortality rates were age standardized by the 2000 Brazilian population.

Findings. A total of 237946 deaths $(8.8 \%)$ were related to diabetes; in $4.2 \%$ of deaths it was the underlying cause and in 4.6\% it was an associated cause. Between 1999 and 2003, agestandardized mortality rates for diabetes as the underlying cause increased $14 \%$ among males and $9 \%$ among females, while mortality with diabetes as an associated cause increased $22 \%$ and $28 \%$, respectively. Diabetes appeared more often as an associated cause in death certificates among older individuals and in those residing in São Paulo State; it appeared less often as an associated cause among women, brown-and black-skinned populations, and in deaths occurring outside hospitals. Cardiovascular diseases accounted for $54.5 \%$ of the underlying causes of death when diabetes was an associated cause.

Conclusion. Diabetes was related to almost $9 \%$ of the deaths in the South and Southeast regions of Brazil. Mortality from diabetes is increasing, especially deaths with diabetes as an associated cause. The probability of having diabetes as the underlying cause of death is greater among women and nonwhite individuals. Our results reinforce the importance of using multiple causes of death to monitor diabetes, because half the individuals with the disease will die of another cause, especially cardiovascular diseases.

Key words Diabetes mellitus; mortality; causes of death; death certificates; Brazil.

Type 2 diabetes is one of the 10 leading causes of death in the world. World Health Organization estimates

\footnotetext{
${ }^{1}$ Universidade Federal de Minas Gerais, Av. Prof. Alfredo Balena 190, Belo Horizonte, MG 30130-100, Brazil. Send correspondence to: Sandhi Maria Barreto, Universidade Federal de Minas Gerais, Av. Prof, Alfredo Balena 190, Belo Horizonte, MG 30130100, Brazil; telephone: 553132489938.
}

(1) indicate a rapid increase in the prevalence of the disease worldwide, especially in developing countries, as a result of aging and of nutritional changes in these countries. Between 1995 and 2025, diabetes prevalence in the population 20 years old or older may have increased around $335 \%$ in Latin America. In 1998, Brazil had about 4.9 million adults with diabetes.
In 2025 , that number is expected to reach about 11.6 million (2).

Diabetes is an important predictor of premature mortality as it is associated with a substantial increase in mortality from all causes, especially coronary heart diseases (3-7). Adverse effects of diabetes extend to all components of the cardiovascular system-the microvasculature, the larger arteries, and 
the heart-as well as to the kidneys. In the United States, it is estimated (6) that diabetes is responsible for at least $3.6 \%-5.1 \%$ of all adult deaths and for $5.2 \%-6.8 \%$ of adult deaths due to cardiovascular diseases. However, death certificates appear to underestimate the importance of diabetes among adults, showing a biased picture of the disease and causes of death among those with diabetes $(8,9)$.

Few studies exist on the evolution of diabetes-related mortality in Brazil (10-12). National mortality estimates are based on a simple analysis of the underlying cause of death listed on death certificates. However, patients with type 2 diabetes who are adequately treated usually die of chronic complications of the disease, which are considered secondary causes on the death certificate (8). Thus, the importance of diabetes as a cause of death is underestimated in studies based solely on underlying causes of death.

The quality of data on mortality varies in Brazil and must be considered to obtain a reliable estimate of diabetes-related mortality. In 2001, mortality system coverage (13) was $93 \%$ in the South region of the country, $89 \%$ in the Southeast, $84 \%$ in the Center-West, $72 \%$ in the Northeast, and $66 \%$ in the North. Moreover, the proportion of deaths from ill-defined conditions was high in the North and Northeast regions (13). For these reasons, this study was restricted to mortality data from the South and Southeast regions.

This study aims to: (1) estimate mortality from diabetes as an underlying and associated cause of death in adults residing in the South and Southeast regions between 1999 and 2003, (2) investigate whether the presence of diabetes as an associated cause on death certificates varies according to selected sociodemographic characteristics, and (3) identify the main underlying causes of deaths related to diabetes.

\section{MATERIALS AND METHODS}

Data were obtained from the Brazilian Mortality Information System, which provides underlying cause of death, date, location of death, and selected characteristics of the deceased. The analysis presented in this manuscript was approved by the Departments of Social and Preventive Medicine and Internal Medicine of the Faculty of Medicine, Federal University of Minas Gerais. Data on mortality do not identify individuals and are freely accessible on the Internet without approval from the Ministry of Health.

All deaths of adults aged 30 years or older residing in the South and Southeast regions of Brazil between 1999 and 2003 were analyzed. The Southeast region is the most developed and populous area in the country (14), with 72412411 inhabitants, $42.64 \%$ of the Brazilian population (169 799170 inhabitants), living in four states: São Paulo (37 032403 inhabitants), Minas Gerais (17 891494 inhabitants), Rio de Janeiro (14 391282 inhabitants), and Espírito Santo (3 097232 inhabitants). The South region of the country accounts for $14.8 \%$ of the Brazilian population living in three states: Rio Grande do Sul (10 187798 inhabitants), Paraná (9 563458 inhabitants), and Santa Catarina (5 356360 inhabitants).

All deaths with underlying cause codes E10 to E14 of the Tenth Revision of the International Classification of Disease (ICD-10) were selected. The presence of diabetes as an associated cause of death was investigated by searching for codes E10 to E14 in all parts of the death certificate (15): in part I on lines Ia (disease or pathological disorder leading to death), Ib (disease or condition causing the immediate cause of death), Ic (the condition present before and leading to the intermediate or immediate cause of death), and Id (filled whenever there is more than one cause regarded as $\mathrm{Ib}$, in which case it is placed in line Ic); and in part II (disease(s) that may have contributed to the death but were not part of the main causal sequence).

Any death with diabetes mentioned in any part of the death certificate was selected and included in the analysis of diabetes as an associated cause. The underlying causes of death in the records that mention diabetes as an associated cause were also identified and grouped by ICD-10 chapter. Information on age, sex, skin color (as reported in the death certificate: white, brown, black, and other), federative unit of residence, and place of death (hospital, household, or other) was obtained. Data were processed and analyzed by Stata (16).

To control for the effect of age distribution variations in the study period and among capitals, mortality rates by sex were directly standardized, having as references the population age distribution in the 2000 demographic census. Mortality trends related to diabetes in the period studied were investigated graphically.

The effect of selected variables on diabetes-related death was tested using Pearson's $\chi^{2}$ test. Multiple logistic regression analysis (17) was used to investigate the association between these selected factors and reporting diabetes as an associated cause, adjusting for age and sex. The magnitude of the associations was measured by an odds ratio with $95 \%$ confidence intervals.

\section{RESULTS}

Between 1999 and 2003, 237946 diabetes-related deaths occurred, which corresponds to $8.8 \%$ of the total deaths in that period. In total, $4.2 \%$ of death certificates had diabetes as the underlying cause and $4.6 \%$ had it as an associated cause. Diabetes, as an associated cause, appeared mainly in part II of the death certificate-that is, as a significant condition contributing to death but not an underlying cause. In these cases, the frequencies with which diabetes appeared in part II of the death certificate were $87.3 \%$, $90.1 \%, 91.3 \%, 93.4 \%$, and $93.5 \%$ in 1999 to 2003 , respectively.

For the 5 years studied, the crude mortality rate from diabetes as an underlying cause remained relatively stable, around 50 per 100000 inhabitants. However, the crude mortality rate based on diabetes as an associated cause of death increased 11\%: from 52.5 per 100000 inhabitants in 1999 to 
58.4 per 100000 in 2003. In absolute numbers, total deaths from diabetes as an underlying cause increased from 21300 to 23628 and deaths reporting diabetes as an associated cause rose from 21598 to 27094 .

Table 1 shows annual age-standardized mortality rates related to diabetes for each sex. Higher mortality rates were observed for females. In the 5-year period, rates for diabetes as an underlying cause increased $14 \%$ among males and 9\% among females. Rates based on deaths with diabetes as an associated cause increased even more: $22.2 \%$ for males and $27.8 \%$ for females.

The mortality rates by age for each sex are shown in Table 2. When the initial and final age groups are compared, a > 100-fold increase in mortality rate is observed for both sexes, regardless of whether diabetes is an underlying or an associated cause of death.

Table 3 shows the distribution of deaths related to diabetes by selected characteristics obtained from death certificates. There is a clear discrepancy in the distribution of death among the states; in São Paulo, mortality was higher for diabetes as an associated cause, while in Rio de Janeiro and Minas Gerais it was higher as an underlying cause. Diabetes was more commonly reported as an associated cause of death among people classified as white or other skin color (which includes mainly people of Japanese origin) than among those declared as having black or brown skin color. Diabetes as an associated cause of death also occurred more frequently in hospitals than elsewhere.

Table 4 shows the results of the analysis comparing deaths with diabetes as an associated cause with deaths having diabetes as an underlying cause, before and after adjustment by all the other factors in the table. Diabetes as an associated cause was significantly less frequent among women and was more prevalent in older age groups. It remained lower in the brown and black populations and among deaths occurring outside the hospital. Compared with São Paulo
TABLE 1. Age-standardized diabetes-related mortality (rate per 100,000 inhabitants) by sex, South and Southeast Brazil, 1999-2003a

\begin{tabular}{cccccc}
\hline & \multicolumn{2}{c}{ Female } & & \multicolumn{2}{c}{ Male } \\
\cline { 2 - 3 } \cline { 5 - 6 } Year & Underlying cause & Associated cause & & Underlying cause & Associated cause \\
\hline 1999 & 52.97 & 50.80 & & 41.98 & 45.83 \\
2000 & 57.75 & 58.95 & & 46.52 & 50.16 \\
2001 & 55.29 & 59.56 & & 44.70 & 50.95 \\
2002 & 57.37 & 62.91 & & 46.05 & 54.31 \\
2003 & 57.65 & 64.94 & & 47.84 & 56.02 \\
\hline
\end{tabular}

a Rate was standardized by the Brazilian population in 2000.
State, the other states were less likely to report diabetes as an associated cause of death.

Cardiovascular diseases accounted for $54.5 \%$ of the underlying causes when diabetes is mentioned as an associated cause, respiratory diseases for $16 \%$, and cancer for $10.9 \%$. Among cardiovascular diseases, coronary heart disease (ICD-10 I20-I25) was the most frequent underlying cause of death, accounting for around $36.6 \%$ of these deaths in 2003.

\section{DISCUSSION}

The analysis of the role of diabetes as an underlying or associated cause of death in populations of states in the South and Southeast regions of Brazil shows that diabetes-related mortality in Brazil is twice as high as that inferred only by the underlying cause of death and that the distribution between underlying and associated cause varies among states, by socio- demographic characteristics, and by place of death.

In death certificates reporting diabetes, its proportion as the underlying cause of death is far higher in Brazil than that found in longitudinal studies (11) and in mortality studies in developed countries (18). In the United States (19), diabetes appears as an associated cause in about two-thirds of the death certificates that mention diabetes anywhere. The same is observed (20) in studies of cohorts of diabetic individuals, in which fewer than onethird of deaths report diabetes as the underlying cause.

It is possible that data obtained from death certificates underestimate the real importance of diabetes in the country, especially as a contributing cause of death, as observed (18-22) in some developed countries.

Age standardization revealed a real increase in mortality rates based on diabetes as an associated cause in the study period. Part of such an increase possibly reflects improvements in the
TABLE 2. Diabetes-related mortality rates by age group and according to position of diabetes on the death certificate in men and women, South and Southeast Brazil, $2000^{\mathrm{a}}$

\begin{tabular}{lccccr}
\hline & \multicolumn{3}{c}{ Male } & & \multicolumn{2}{c}{ Female } \\
\cline { 2 - 3 } $\begin{array}{c}\text { Age } \\
\text { (years) }\end{array}$ & $\begin{array}{c}\text { Underlying } \\
\text { cause }\end{array}$ & $\begin{array}{c}\text { Associated } \\
\text { cause }\end{array}$ & & $\begin{array}{c}\text { Underlying } \\
\text { cause }\end{array}$ & $\begin{array}{c}\text { Associated } \\
\text { cause }\end{array}$ \\
\hline $30-39$ & 3.91 & 3.03 & & 2.88 & 2.00 \\
$40-49$ & 13.79 & 11.77 & & 9.79 & 8.25 \\
$50-59$ & 45.59 & 45.59 & 43.09 & 38.61 \\
$60-69$ & 120.48 & 129.28 & 122.45 & 122.77 \\
$70-99$ & 231.62 & 271.15 & 267.53 & 285.96 \\
$\geq 80$ & 343.14 & 411.06 & 471.48 & 521.16 \\
\hline
\end{tabular}

a Rate per 100,000 inhabitants. 
TABLE 3. Distribution of deaths related to diabetes according to its position on death certificate and by selected characteristics in adults residing in South and Southeast Brazil, 1999-2003

\begin{tabular}{|c|c|c|c|c|c|c|}
\hline \multirow[b]{3}{*}{ Characteristic $^{a}$} & \multicolumn{4}{|c|}{ Diabetes on death certificate } & \multirow{3}{*}{$\begin{array}{c}\text { Total number } \\
\text { of deaths }\end{array}$} & \multirow{3}{*}{$\begin{array}{c}A C-U C \\
\%\end{array}$} \\
\hline & \multicolumn{2}{|c|}{ Underlying cause (UC) } & \multicolumn{2}{|c|}{ Associated cause (AC) } & & \\
\hline & $N$ & $\%$ & $N$ & $\%$ & & \\
\hline \multicolumn{7}{|l|}{ Sexb } \\
\hline Male & 48102 & 46.89 & 54485 & 53.11 & 102587 & 6.22 \\
\hline Female & 65774 & 48.61 & 69547 & 51.39 & 135324 & 2.78 \\
\hline \multicolumn{7}{|l|}{ Age group (years) ${ }^{c}$} \\
\hline $30-39$ & 2468 & 55.99 & 1940 & 44.01 & 4408 & -11.98 \\
\hline $40-49$ & 7152 & 54.39 & 5998 & 45.61 & 13150 & -8.78 \\
\hline $50-59$ & 17081 & 50.70 & 16607 & 49.30 & 33688 & -1.40 \\
\hline $60-69$ & 29779 & 49.05 & 30933 & 50.95 & 60712 & 1.90 \\
\hline $70-79$ & 36834 & 48.73 & 38755 & 51.27 & 75589 & 2.54 \\
\hline$\geq 80$ years & 23084 & 46.79 & 26250 & 53.21 & 49334 & 6.42 \\
\hline \multicolumn{7}{|l|}{ State of residence ${ }^{d}$} \\
\hline São Paulo & 35967 & 40.12 & 53660 & 59.88 & 89627 & 19.76 \\
\hline Minas Gerais & 22562 & 54.77 & 18633 & 45.23 & 41195 & -9.54 \\
\hline Espírito Santo & 5889 & 55.27 & 4767 & 44.73 & 10656 & -10.54 \\
\hline Rio de Janeiro & 26106 & 55.20 & 21190 & 44.80 & 47296 & -10.40 \\
\hline Paraná & 10454 & 59.56 & 7097 & 40.44 & 17551 & -19.12 \\
\hline Santa Catarina & 4511 & 49.67 & 4552 & 50.23 & 9063 & 0.56 \\
\hline Rio Grande do Sul & 11020 & 50.81 & 10667 & 49.19 & 21687 & -1.62 \\
\hline \multicolumn{7}{|l|}{ Skin colore } \\
\hline White & 74831 & 46.84 & 84943 & 56.17 & 159774 & 9.33 \\
\hline Black & 9858 & 55.41 & 7933 & 44.59 & 17791 & -10.82 \\
\hline Brown & 16810 & 53.59 & 14577 & 46.41 & 31387 & -7.18 \\
\hline Other & 1357 & 43.49 & 1763 & 56.51 & 3120 & 13.02 \\
\hline \multicolumn{7}{|l|}{ Place of death ${ }^{\dagger}$} \\
\hline Hospital & 91494 & 47.04 & 103005 & 52.96 & 194499 & 5.92 \\
\hline Domicile & 17916 & 57.60 & 13186 & 42.40 & 31102 & -15.20 \\
\hline Other & 3417 & 55.02 & 2793 & 44.98 & 6210 & -10.04 \\
\hline
\end{tabular}

recording of associated causes on death certificates, supporting the idea of underestimation of diabetes as a contributory cause on death certificates. On the other hand, a real increment in mortality from diabetes cannot be denied. The increased incidence in the disease observed in many countries and the strong relationship to aging and to obesity also has a positive impact on mortality as cohorts with a higher incidence of diabetes are reaching older ages. Though suggestive, it cannot be asserted that the incidence of diabetes has been increasing in Brazil because of the lack of populationbased studies of the disease.

When comparing data from a study (11) on mortality from diabetes as an underlying and an associated cause in the State of São Paulo in 1992, a real increment in mortality from diabetes may be inferred. That year, of a total 202141 deaths in the state, diabetes was mentioned on 13786 (6.8\%) certificates: $2.6 \%$ as underlying cause and $4.2 \%$ as associated cause of the total deaths. In 2000, 20934 deaths from diabetes were recorded in the state, six times more than in 1992, representing $10.3 \%$ of the total deaths that occurred that year. However, the percentage distribution of deaths referring to diabetes as an underlying and an associated cause was similar: $38.5 \%$ and $61.5 \%$ in 1992 and $40.1 \%$ and $59.9 \%$ in 2000, respectively.

The observed increase in the frequency with which diabetes appears as an associated cause of death may re- flect real differences in disease survival and improvements in filling out death certificates. Studies in developed countries in the 1980s and 1990s $(20,23-25)$ show that diabetes was referred to as a contributory cause in fewer than $40 \%$ of the death certificates of diabetic patients. The distribution of diabetes-related mortality in São Paulo is similar to that in developed countries (26), which suggests better disease control in the state, leading to a reduction in premature mortality, which more often attributes diabetes as an underlying cause.

An increase in the presence of diabetes as an associated cause on death certificates related to age is observed in numerous longitudinal studies and partially indicates greater death risk from 
TABLE 4. Characteristics associated with reporting diabetes as a contributory cause on death certificate, South and Southeast Brazil, 2003

\begin{tabular}{|c|c|c|c|c|}
\hline Characteristic & $\mathrm{OR}^{\mathrm{a}}$ & $95 \% \mathrm{Cl}^{\mathrm{b}}$ & Adjusted $\mathrm{OR}^{\mathrm{c}}$ & $95 \% \mathrm{Cl}$ \\
\hline \multicolumn{5}{|l|}{ Sex } \\
\hline Male & 1.00 & $N A^{d}$ & & NA \\
\hline Female & 0.96 & $0.93-0.99$ & 0.95 & $0.91-0.98$ \\
\hline \multicolumn{5}{|l|}{ Age (years) } \\
\hline $30-39$ & 1.00 & NA & 1.00 & NA \\
\hline $40-49$ & 1.43 & 1.2191 .70 & 1.44 & $1.20-1.73$ \\
\hline $50-59$ & 1.52 & $1.30-1.79$ & 1.50 & $1.27-1.78$ \\
\hline $60-69$ & 1.79 & $1.53-2.09$ & 1.81 & $1.54-2.13$ \\
\hline $70-79$ & 1.82 & $1.56-2.13$ & 1.82 & $1.54-2.14$ \\
\hline$\geq 80$ & 1.82 & $1.56-2.13$ & 1.83 & $1.55-2.16$ \\
\hline \multicolumn{5}{|l|}{ Skin color } \\
\hline White & 1.00 & NA & 1.00 & NA \\
\hline Black & 0.67 & $0.63-0.72$ & 0.73 & $0.68-0.79$ \\
\hline Brown & 0.73 & $0.69-0.77$ & 0.79 & $0.74-0.83$ \\
\hline Other & 1.26 & $1.06-1.50$ & 1.04 & $0.87-1.24$ \\
\hline \multicolumn{5}{|l|}{ Place of death } \\
\hline Hospital & 1.00 & NA & 1.00 & NA \\
\hline Household & 0.56 & $0.53-0.560$ & 0.56 & $0.53-0.59$ \\
\hline Other & 0.91 & $0.84-0.99$ & 0.77 & $0.70-0.84$ \\
\hline \multicolumn{5}{|l|}{ State of residence } \\
\hline São Paulo & 1.00 & NA & 100 & NA \\
\hline Minas Gerais & 0.56 & $0.53-0.59$ & 0.61 & $0.57-0.65$ \\
\hline Espírito Santo & 0.60 & $0.54-0.68$ & 0.66 & $0.58-0.76$ \\
\hline Rio de Janeiro & 0.52 & $0.49-0.55$ & 0.54 & $0.52-0.57$ \\
\hline Paraná & 0.51 & $0.48-0.55$ & 0.53 & $0.50-0.57$ \\
\hline Santa Catarina & 0.69 & $0.63-0.75$ & 0.71 & $0.64-0.78$ \\
\hline Rio Grande do Sul & 0.57 & $0.54-0.61$ & 0.55 & $0.52-0.59$ \\
\hline
\end{tabular}

the disease and its direct complications for young adults. At the same time, an increase in the prevalence of comorbidities with age is expected. It is estimated that, of the 7.5 million diabetes-related deaths in the world in 2000, 4.6 million occurred for reasons other than diabetes. For individuals aged 35-69, 59\% of deaths were attributed to diabetes, while for individuals over 64 with diabetes, only $29 \%$ of deaths were attributed to the disease (9).

This study identified a significant variation in the frequency with which diabetes is mentioned as a related cause of death according to age, sex, skin color/race, place of residence, and place of death. Similar variations have also been reported in the United States and may be attributed to systematic bias affecting information quality and completeness, from medical diagnosis to final coding and pro- cessing of the underlying cause of death. If a death certificate lists only one cause, then it must be selected as the underlying cause and there will not be multiple causes in such a case (22). If diabetes were underreported as a contributory cause in states other than São Paulo, then the real burden of diabetes mortality would be even greater and would increase in the near future, as reporting of multiple causes tends to improve.

The cause of death depends on the history of the disease that led to death. If we consider that the reporting of multiple causes of death is a proxy for the level of familiarity between the death certifier and the patient, then it can be expected that a death that occurs in a hospital, compared with deaths away from a hospital environment, will more often contain information on associated causes of death, possibly because of better documentation of the patient's health. Our results support this hypothesis.

When we analyze mortality by sex, a larger proportion of male deaths under 60 years is observed, with inversion at more advanced ages, for diabetes as an underlying cause and as an associated cause. Several studies have shown that mortality from diabetes varies with age and sex. Lower female mortality is observed for young adults both with and without diabetes, with inversion at more advanced ages. In a study in the United States (21), median life expectancy for females with diabetes at 55-64 years of age was 17 years compared with 10 years for males with diabetes in the same condition and the same age. However, diabetes prevalence is usually higher in females than in males and the risk of death associated with the disease is also higher in females than in males (6). Based on longitudinal studies in several developed countries (9), the relative risk has been estimated at 4.05 , 2.86, and 1.46 for males in the 20-39, $50-59$, and 60-79 age groups and at $6.72,3.54$, and 2.25 for females in the same age groups, respectively.

The greater probability of the presence of diabetes as the underlying cause of death in females, in people with brown or black skin, and in deaths occurring away from a hospital environment observed in the present study has also been reported in a study (19) on the factors associated with the report of multiple causes of death in the United States. Such findings suggest that factors other than those expected in the disease's natural history operate in the certification of causes of death. On the other hand, if we consider that the selection of diabetes as an associated cause of death is a desirable proxy for better control of the disease, and therefore for the reduction in precocious mortality from its direct complications, our results suggest a worse prognosis of the disease for women and nonwhites in the country. Because odds ratios tend to overestimate the magnitude of the association in crosssectional studies, especially when the prevalence of the condition being ana- 
lyzed is high, we also calculated prevalence ratios (27). Compared with the odds ratios displayed in Table 4, the prevalence ratios obtained by Poisson regression were slightly smaller than the corresponding odds ratios and confidence intervals were narrower, but the directions of the associations remained the same (data not presented).

The predominance of cardiovascular diseases as the underlying cause in deaths of which diabetes is an associated cause is expected for several reasons and has already been reported in the country. In Recife (12), in the Northeast region of the country, cardiovascular diseases were the underlying cause of death in most diabetic patients over age 50 and of acute complications in most diabetic patients under age 50. The risk of cardiovascular disease is markedly higher in diabetic patients, with a prevalence twice as high as that in the general population $(28,29)$. A U.S. study (21) found that coronary disease, cerebrovascular disease, and other heart diseases account for $25.4 \%, 7.75 \%$, and $2.9 \%$ of underlying causes from the total death certificates in which diabetes appears in any position. A metaanalysis of 37 cohorts (4) found a 3fold greater risk of a fatal coronary event in diabetic individuals than in people without diabetes (5.6 and 1.6), with the relative risk for people with diabetes being $50 \%$ higher for females than for males.

In conclusion, diabetes is a serious disease, with multiple complications and premature mortality being related to almost $9 \%$ of the deaths in the first and third most densely inhabited regions of Brazil (South and Southeast). The importance of using multiple causes of death to monitor diabetes is clear, as more than half the individuals with the disease will die of another cause, especially cardiovascular diseases. Our results show that women and nonwhites die more often from the disease itself. Possible inequalities in reporting the causes of death should be investigated.

\section{REFERENCES}

1. World Health Organization. Diabetes Programme [Web site]. Available from: http:// www.who.int/diabetes/en/. Accessed 8 March 2007.

2. King H, Aubert RE, Herman WH. Global burden of diabetes, 1995-2025: Prevalence, numerical estimates and projections. Diabetes Care. 1998;21(9):1414-31.

3. Lotufo PA, Gaziano JM, Chae CU, Ajani UA, Moreno-John G, Buring JE, et al. Diabetes and all-cause and coronary heart disease mortality among US male physicians. Arch Intern Med. 2001;161(2):242-7.

4. Huxley R, Barzi F, Woodward M. Excess risk of fatal coronary heart disease associated with diabetes in men and women: metaanalysis of 37 prospective cohort studies. BMJ. 2006;332(7533):73-8.

5. Hu FB, Stampfer MJ, Solomon CG, Liu S, Willett WC, Speizer FE, et al. The impact of diabetes mellitus on mortality from all causes and coronary heart disease in women: 20 years of follow-up. Arch Intern Med. 2001;161(14):1717-23.

6. Saydah SH, Eberhardt MS, Loria CM, Brancat FL. Age and burden of death attributable to diabetes in the United States. Am J Epidemiol. 2002;156 (8):714-9.

7. Whiteley L, Padmanabhan S, Hole D, Isles C. Should diabetes be considered a coronary heart disease risk equivalent? Diabetes Care. 2005;28(7):1588-93.

8. McEwen LN, Kim C, Haan M, Ghosh D, Lantz PM, Mangione CM, et al. Diabetes reporting as a cause of death: Results from the Translating Research Into Action for Diabetes (TRIAD) study. Diabetes Care. 2006;29(2): 247-53.

9. Roglic G, Unwin N, Bennett PH, Mathers C, Tuomilehto J, Nag S, et al. The burden of mortality attributable to diabetes. Realistic estimates for the year 2000. Diabetes Care. 2005;28(9):2130-5.
10. Coeli CM, Ferreira LGFD, Derbal MM, Veras RP, Camargo KR Jr, Cascão AM. Diabetes mellitus mortality among elderly as an underlying or secondary cause of death. Rev Saude Publica. 2002;36(2):135-40.

11. Laércio FJ, Mameri C, Pagliaro H, Iochida LC, Goldenberg P. Diabetes as underlying or associated cause of death in the State of S. Paulo, Brazil, 1992. Rev Saude Publica. 1998;32(3):237-45.

12. Melo SM, Lolio CA, Lucena MAF, Kirzner CF, Martins SM, Barros MNDS. Multiple causes of death in diabetic individuals in the Brazilian Northeastern Region. Rev Saude Publica. 1991;25(6):435-42.

13. Ministry of Health. Brazil Health 2005: An analysis of health situation at Brazil [Web site]. 2005. Available from: http://portal. saude.gov.br/portal/arquivos/pdf/saude brasil 2005.pdf. Accessed 24 January 2007.

14. Brazilian Institute of Geography and Statistics [Web site]. Available from: http://www. ibge.gov.br/home. Accessed 15 January 2007.

15. Morritt NA, Hall J. Completing a death certificate. BMJ Career Focus. 2004:328:217.

16. Stata Statistical Software [computer program]. Release 8.0. College Station, TX: Stata Corporation; 2002.

17. Hosmer DW, Lemenshow S. Applied logistic regression. New York: John Wiley and Sons; 1989.

18. Boyko EJ. Progress in the estimation of mortality due to diabetes. Diabetes Care. 2005;28(9):2320-1.

19. Wall MM, Huang J, Oswald J, McCullen D. Factors associated with reporting multiple causes of death. BMC Med Res Methodol. 2005;5(1):4.

20. Tseng $\mathrm{CH}$. Mortality and causes of death in a national sample of diabetic patients in Taiwan. Diabetes Care. 2004;24:1605-9.

21. Penman A. Excess mortality due to diabetes in Mississippi and the estimated extent of un- derreporting on death certificates. J Miss State Med Assoc. 2004;44(10):219-52.

22. Whittall DE, Glatthaar C, Knuiman MW, Welborn TA. Deaths from diabetes are underreported in national mortality statistics. Med J Aust. 1990;152(11):598-600.

23. Vauzelle-Kervroedan F, Delcourt C, Forhan A, Jougla E, Hatton F, Papoz L. Analysis of mortality in French diabetic patients from death certificates: a comparative study. Diabetes Metab. 1999;25(5):404-11.

24. Thomason MJ, Biddulph JP, Cull CA, Holman RR. Reporting of diabetes on death certificates using data from the UK Prospective Diabetes Study. Diabet Med. 2005;22(8): 1031-6.

25. Gu K, Cowie CC, Harris MI. Mortality in adults with and without diabetes in a national cohort of the U.S. population, 19711993. Diabetes Care. 1998;21(7): 1138-45.

26. Will JC, Vinicor F, Stevenson J. Recording of diabetes on death certificates: Has it improved? J Clin Epidemiol. 2001;54:239-44.

27. Barros AJ, Hirakata VN. Alternatives for logistic regression in cross-sectional studies: an empirical comparison of models that directly estimate the prevalence ratio. BMC Med Res Methodol. 2003;20:3-21.

28. Report of Expert Committee on the Diagnosis and Classification of Diabetes Mellitus. Diabetes Care. 2003;26(Suppl 1):S5-20.

29. Zachary T, Bloomgarden MD. Consequences of diabetes. Cardiovascular disease. Diabetes Care. 2004;27:1825-31.

Manuscript received 8 March 2007. Revised version accepted for publication 9 July 2007. 
RESUMEN Objetivos. Estimar las muertes relacionadas con la diabetes en adultos brasileños entre 1999 y 2003 y analizar los factores demográficos asociados con el informe de la diabetes como causa asociada de muerte.

\section{Aumento de la carga de la mortalidad por diabetes en adultos brasileños}

Palabras clave
Métodos. Se identificaron todas las muertes en que la diabetes fue la causa principal o asociada, a partir del Sistema Brasileño de Datos de Mortalidad. El análisis se realizó según el sexo, la edad, el año, el estado de residencia y el lugar de muerte. Las tasas de mortalidad se estandarizaron por la edad según la población brasileña en 2000.

Resultados. En total, 237946 muertes (8,8\%) estuvieron relacionadas con la diabetes; en $4,2 \%$ de las muertes, la diabetes fue la causa principal y en $4,6 \%$ fue una causa asociada. Entre 1999 y 2003, las tasas de mortalidad estandarizadas según la edad para las muertes en que la diabetes fue la causa principal aumentaron $14 \%$ en hombres y $9 \%$ en mujeres, mientras que la mortalidad con la diabetes como causa asociada aumentó a $22 \%$ y $28 \%$, respectivamente. La diabetes apareció más frecuentemente como causa asociada en los certificados de defunción de la personas de mayor edad y en los que residían en el Estado de São Paulo, mientras que fue menos frecuente en mujeres, negros y mestizos y cuando la muerte ocurrió fuera de los hospitales. Las enfermedades cardiovasculares fueron la causa principal de $54,5 \%$ de las muertes en las que la diabetes se consideró como causa asociada.

Conclusiones. La diabetes estuvo relacionada con casi $9 \%$ de las muertes ocurridas en las regiones sur y suroriental de Brasil. La mortalidad por diabetes está en aumento, especialmente cuando la diabetes figura como causa asociada de muerte. La probabilidad de tener diabetes como causa principal de muerte es mayor en mujeres y en personas que no son blancas. Estos resultados confirman la importancia de utilizar la información de las múltiples causas de muerte para analizar la diabetes, ya que la mitad de las personas con esta enfermedad morirá por otra causa, especialmente por enfermedades cardiovasculares.

Diabetes mellitus, mortalidad, causas de muerte, causa de muerte, certificado de defunción, Brasil.

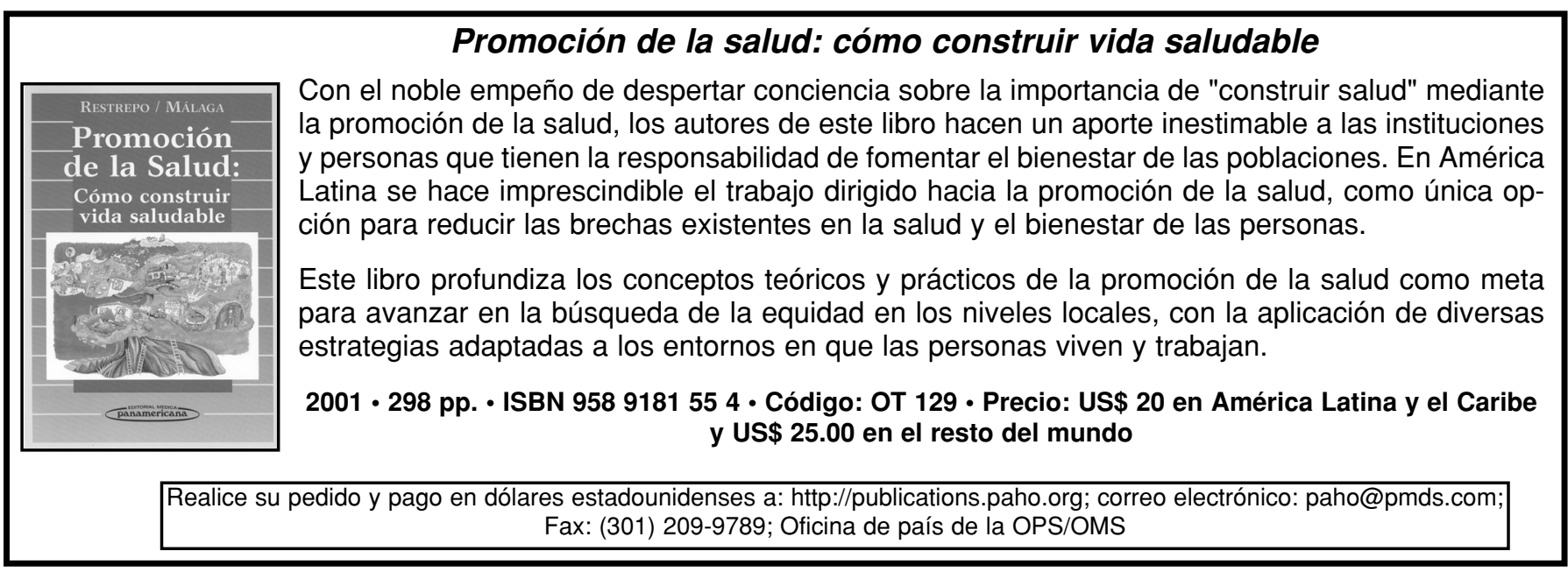

